\title{
Bock, Julia. 2019. The Treatment of Hungarian Jewish Health Professionals in the Shadow of the Holocaust. Newcastle upon Tyne: Cambridge Scholars Publishing.
}

\section{Reviewed by Andrew J. Lee, ${ }^{*}$ Northern Virginia Community College}

The books that make up the historical record and detail the fate of Hungarian Jews in World War II are certainly not lacking for breadth and often depth. While numerous volumes cover aspects of the Shoah, from the general fate of Hungarian Jews to very specific biographic explorations, a volume exploring the fate of a group of professionals has been missing from this history. Fortunately, historian Julia Bock, of Long Island University in Brooklyn, New York, fills this gap by chronicling the experiences of Hungarian Jewish medical professionals, focusing primarily on medical doctors before, during, and after World War II. Bock details aspects of these disrupted lives in her recently published book The Treatment of Hungarian Jewish Health Professionals in the Shadow of the Holocaust and largely succeeds in uncovering a compelling history told through patchwork stories of lives shattered.

Though narratives documenting the treatment of Jews at the hands of Nazis during World War II are extensive, books continue to be published and run a gamut of topics explored. Ranging from broad academic texts detailing cultural aspects of Hungarian Jews to popular press offerings, these works play a valuable role in publicizing the Hungarian Jewish perspective of World War II civilian suffering. Julia Bock contributes the fruits of her research to deliver an easy-to-read and thorough account of the Hungarian-Jewish medical community in the turbulent years surrounding World War II. From the stories of the Jewish doctors working in the Budapest ghetto, to the attempts at providing medical care in forced labor camps (while lacking basic medical supplies), the reader is introduced to engaging narratives that tell a compelling history through short vignettes. One can readily imagine the difficult circumstances facing doctors who were sent to extermination camps, yet still were compelled to use their training to treat fellow Jews. In retrospect, their predicament and conduct offer tantalizing possibilities for exploring how their difficult situation unfolded and how they coped with the emotional burden while carrying out professional duties.

In her Introduction, Bock states that she wishes to fill gaps in the historical record by memorializing the lost talent, describing the lives disrupted, and detailing the ultimate successes of Hungarian-Jewish doctors. Accordingly, her work is mostly focused on biographical facts related to time, place, and events. Bock has extensively researched and provided important information about the many notable Hungarian-Jewish medical professionals who survived to

*andrewjlee@pm.me

$($ (c) $)$ EY

ULIS D-Serke
New articles in this journal are licensed under a Creative Commons Attribution 4.0 International License.

This journal is published by the University Library System of the University of Pittsburgh as part of its D-Scribe Digital Publishing Program and is cosponsored by the University of Pittsburgh Press 
form an elite medical diaspora extending from Istanbul to New York. Though the details are expansive, the disjointed accounting of these lives reads like thumbnail sketches characteristic of the biographies found in a medical society roster. What seems to be lacking are the granular details that would have been possible through interviews with the profiled individuals or, owing to the march of time, their next of kin.

Bock's methodology of research is clearly stated and she describes how she accessed multiple archives to profile nearly two thousand medical doctors in addition to other medical professionals. The starting point for her search centered on the NAMES project of the Jerusalem Yad Vashem World Holocaust Remembrance Center, which is based in part on the Center's decade-long collection of Pages of Testimony from survivors, relatives of victims and others who had/have knowledge of lost individuals and communities. As Bock helpfully points out, the exhaustive research she conducted went beyond published materials and involved accessing archives in Hungary, Israel, and the United States. The Introduction thus makes clear her goal of collecting and sorting data to relay information that impacted a particular segment of HungarianJewish society over three generations. It becomes clear that this project has been a work in the making for many years. The antecedents and sparks of interest go back to 2012 and 2015 to include the journal articles and book reviews that Bock wrote. Her 2012 book review of a Hungarian-language text detailing the forced labor used at a metal mine in Bor, Serbia is one of the issues that Bock describes in this book. Also, an academic article of hers appearing in Clinics in Dermatology from 2015 traces the fate of Hungarian-Jewish dermatologists during World War II. The long bibliography demonstrates the extensive research conducted by Bock.

Despite the book's utility, a handful of weaknesses detract from the service it provides to the reader. From a macroscopic perspective, the weaknesses range from the staccato prose style to the limited explanations of events within their relevant context, often leaving the reader wanting more and wishing for an expanded description of many events. While the purpose of the book was not to tell a complete story of a handful of episodes, the telling of stories leaves the reader longing for a fuller narrative. Whether the lacking longer-form exposition is due to poor records, the death of survivors, or avoidance of in-depth narrative remains unclear. It is also unclear whether a weakness in Bock's research relates to her focus on doctors in Budapest (and to a lesser degree Debrecen), and to the near exclusion of physicians hailing from, practicing in, or affiliated with Szeged and Pécs universities. The reader is left to wonder if her research did not extend to these corners of Hungary or whether the records were incomplete owing to their geographic distance from Budapest. While inhabitants of Pécs and Szeged are mentioned in the list of names occupying one third of the book, there lacks a similar representation in the longerform biographies that occupy a paragraph or two and feature some photographs.

Given the book's publication in English, it is presumed that a goal of this work is to reach a larger audience, specifically, an audience beyond those in Hungary, whose family suffered in World War II, or readers with a historical interest. For those unable to read Hungarian or who are not as familiar with Hungarian historical events, a Glossary of terms (including significant geographic locations and abbreviations) would have made things more accessible to a broader readership. For example, the fascist Hungarian Arrow Cross Party (that ruled Hungary during 1944-1945) is arguably not well known outside Hungary or beyond those circles familiar with history. Given the lack of even a brief explanation about this party in the text, the inclusion of even a short entry about it in a glossary would have been a useful aid to the reader. Similarly, an index would have aided the queries of those readers searching for particular individuals, places, or events. Lastly, a map representing cities and towns in central Europe would have also been of 
Lee, Andrew J. "Bock, Julia. 2019. The Treatment of Hungarian Jewish Health Professionals in the Shadow of the Holocaust. Newcastle upon Tyne: Cambridge Scholars Publishing." Hungarian Cultural Studies. e-Journal of the American Hungarian Educators Association, Volume 13 (2020) DOI: 10.5195/ahea.2020.402

aid in presenting the dramatic narratives and further impact an international audience. Smaller oddities include a non-user-friendly layout, inconsistent type-facing, and irregular formatting throughout the book, all of which distract and make for less-easy reading. These formatting problems do not significantly mar the reader's experience but leave the impression of a less polished book.

This book provides a valuable, important service due to its thorough documentation and use of numerous resources. Presenting short biographies and vignettes, Bock provides a comprehensive, if disjointed, mosaic of this generation, thereby rendering a valuable service for the historical record. There is little doubt that in addition to scholars, the descendants of those whose lives were torn apart by the Second World War will treasure this service to history. In addition, Bock issues a call for assistance asking descendants to contribute their biographies, and this will surely further the legacy of this book. The engaging stories provide incomplete mosaics of what would surely make for an enthralling narrative. What is clear is Julia Bock's dogged, passionate investigation and helpful cataloging of many individuals during and, if applicable, after World War II. 